\title{
G Protein-Gated Inwardly Rectifying Potassium Channel Subunit 3 is Upregulated in Rat DRGs and Spinal Cord After Peripheral Nerve Injury
}

\author{
This article was published in the following Dove Press journal: \\ Journal of Pain Research
}

\author{
Chuang Lyu' \\ Gong-Wei Lyu ${ }^{2}$ \\ Jan Mulder $\mathbb{D}^{3,4}$ \\ Aurora Martinez $\left(\mathbb{D}^{5}\right.$ \\ Tie-Jun Sten Shi $\mathbb{B D}^{5}$ \\ 'State Key Laboratory of Veterinary \\ Biotechnology, Harbin Veterinary Research \\ Institute of Chinese Academy of Agricultural \\ Sciences, Harbin 150069, People's Republic \\ of China; ${ }^{2}$ Department of Neurology, Ist \\ Hospital of Harbin Medical University, \\ Harbin I5000I, People's Republic of China; \\ ${ }^{3}$ Department of Neuroscience, Karolinska \\ Institutet, Stockholm SE-I7I 77, Sweden; \\ ${ }^{4}$ Science for Life Laboratory, Karolinska \\ Institutet, Stockholm SE-17I 65, Sweden; \\ ${ }^{5}$ Department of Biomedicine, University of \\ Bergen, Bergen 5009, Norway
}

Correspondence: Chuang Lyu

Tel +86 I330450350 I

Email htylv123@126.com

Tie-Jun Sten Shi

Tel +47 45392855

Email tiejun.shi@uib.no
Background: G protein-gated inwardly rectifying potassium (GIRK) channels are involved in the regulation of neuronal excitability. Four GIRK subunits (GIRK1-4) are expressed in rat dorsal root ganglia (DRGs). Recently, we have characterized the expression of GIRK1 and -2 , and both are downregulated in rat DRGs and spinal cord after a complete sciatic nerve transection (axotomy). Here, we aimed to study the neurochemical characteristics of GIRK3, and its regulation in rat DRGs and spinal cord induced by nerve injury.

Methods: A sciatic nerve axotomy was performed to study the influences of injury on GIRK3 expression in DRGs and spinal cord. A dorsal root rhizotomy and a sciatic nerve crush were employed to study the axonal transport of GIRK3 protein, respectively. Immunohistochemistry analysis was employed for investigating the neurochemical characteristics of GIRK3.

Results: In control DRGs, $\sim 18 \%$ of neuron profiles (NPs) were GIRK3-positive $\left(^{+}\right.$), and $\sim 41 \%, \sim 48 \%$ and $\sim 45 \%$ of $\mathrm{GIRK}^{+} \mathrm{NPs}$ were $\mathrm{CGRP}^{+}, \mathrm{IB}^{+}$and $\mathrm{NF}^{+} 20^{+}$, respectively. GIRK3-like immunoreactivity was observed in glabrous skin of hind paws and axons originating from DRG neurons. Fourteen days after axotomy, more than one-third of DRG NPs were GIRK $3^{+}$, and among these $\sim 51 \%$ and $\sim 56 \%$ coexpressed galanin and neuropeptide $\mathrm{Y}$, respectively. In control animals, a small group of interneurons found in the dorsal horn was GIRK3 ${ }^{+}$. In addition, GIRK3 ${ }^{+}$processes could be observed in superficial laminae of spinal dorsal horn. After nerve injury, the intensity of GIRK3-like immunoreactivity in the superficial layers was increased. Evidence based on rhizotomy and sciatic nerve crush indicated both anterograde and retrograde transport of GIRK3.

Conclusion: Our study demonstrates that GIRK3 is expressed in sensory neurons and spinal cord. GIRK3 has both anterograde and retrograde axonal transport. GIRK3 expression can be regulated by peripheral nerve injury.

Keywords: GIRK channels, Kir3, axotomy, DRGs, spinal cord, chronic pain

\section{Introduction}

Inhibitory $(\mathrm{Gi} / \mathrm{o}) \mathrm{G}$ protein-coupled receptor signaling pathways regulate membrane excitability in many cell types, including neurons, endocrine cells and cardiac myocytes. ${ }^{1} \mathrm{G}$ protein-gated inwardly rectifying potassium (GIRK) channels are common downstream effectors for PTX-sensitive Gi/o-dependent signaling pathways in the nervous system. ${ }^{2}$ The mechanisms underlying activation of GIRK channels have been explored and evidence shows that GIRK channels are activated by $\mathrm{G}_{\beta \gamma}$ subunits after the ligand binding with the corresponding $\mathrm{G}$ protein-coupled 
receptors. ${ }^{3,4}$ A well-established example is opioid-induced analgesia which involves GIRK channels acting as downstream effectors. ${ }^{5-8}$ In addition, GIRK channels are known to mediate the inhibitory effects of many other neurotransmitters and drugs of abuse. ${ }^{9,10}$ GIRK channel subunits have been detected in dorsal root ganglion (DRG) neurons of rats and humans, ${ }^{11-14}$ and mice. ${ }^{15,16}$ Opiates are known to be highly effective in acute pain and acute inflammatory pain, ${ }^{17-21}$ but are less effective in neuropathic pain patients or animal models. After peripheral nerve injury, the GIRK1 and -2 proteins are significantly downregulated in DRGs and spinal dorsal horn. ${ }^{22}$ This suggests a possible loss of opioid-induced inhibition.

There are four GIRK subunits (GIRK1-4) in mammals, of which GIRK1 and -2 have splice variants, but not GIRK3 or GIRK4. ${ }^{23}$ Functional GIRK channels are composed of homotetramers or heterotetramers. GIRK3 cannot form functional homotetramers ${ }^{24}$ but rather assembles with other GIRK subunits to form functional channels. In addition, GIRK3 is suggested to regulate GIRK signaling differently from other GIRK subunits based on the findings that in GIRK2- and/or 1-knockout (KO) mice, a strong reduction of GIRK current is detected in the brain, ${ }^{25}$ however, GIRK3KO mice exhibit similar currents induced by agonist but less severe sedatives induced withdrawal as compared to wildtype (WT) mice. ${ }^{26}$ In GIRK2-KO mice, massive behavioral abnormalities have been found, whereas GIRK3-KO mice are no different from WT mice in behavioral tests. ${ }^{1,27,28}$ Moreover, a lysosomal targeting sequence in GIRK3 can promote the degeneration of GIRK channels. ${ }^{29}$ All evidence above points out the significance of GIRK3 for GIRK channel function, which is different from other GIRK subunits.

Recently, the expression of GIRK1 and GIRK2 has been studied in rat lumbar (L) DRGs and spinal cord, and both subunits are downregulated by peripheral axotomy. ${ }^{22}$ In this study, the effects of nerve injury on GIRK3 expression were investigated in DRGs and spinal cord, and the axonal transport of GIRK3 was also analyzed.

\section{Materials and Methods}

\section{Animals}

Adult male Sprague-Dawley rats (200-250 g, B\&K Universal, Stockholm, Sweden) were used in this study. The rats were housed 2 or 3 per cage and allowed to access to food and water ad libitum. All experiments were performed according to the Ethical Guidelines of the International Association for the Study of Pain and were approved by the local research ethics committee (Stockholm's Norra Djurförsöksetiska Nämnd (N150/11)).

\section{Surgical Procedures}

The surgery for a unilateral complete sciatic nerve transection (axotomy) was made according to a previous study. ${ }^{30}$ The rats subjected to axotomy were allowed to survive for 14 days. Dorsal root rhizotomy and sciatic nerve crush were performed according to previous procedures. ${ }^{31,32}$ Briefly, both skin and muscles were incised to expose vertebral laminae under deep anesthesia, followed by transection of L2-5 dorsal roots, and finally muscles and skin were sutured. The rats subjected to rhizotomy were allowed to survive for 14 days. The rats subjected to sciatic nerve crush were sacrificed $10 \mathrm{hrs}$ postsurgery.

\section{Immunohistochemistry}

All rats were deeply anesthetized with sodium pentobarbital (50 mg/kg, i.p.). The anaesthetic animals were transcardially perfused with $50 \mathrm{~mL}$ warm saline $\left(0.9 \% ; 37^{\circ} \mathrm{C}\right)$, followed by $50 \mathrm{~mL} \mathrm{4 \%}$ paraformaldehyde, and finally by $250 \mathrm{~mL}$ of the same, but ice-cold fixative. The contra- and ipsilateral DRGs (L4-5), as well as corresponding spinal cord at injured levels, were dissected out and post-fixed in the fixative for $90 \mathrm{~min}$ at $4^{\circ} \mathrm{C}$. Subsequently, all specimens were stored in $10 \%$ sucrose at $4^{\circ} \mathrm{C}$ for 2 days. Tissues were embedded in OCT compound (Tissue Tek, Sakura, Leiden, Netherland), and then sectioned in a cryostat (Microm, Heidelberg, Germany) at $12 \mu \mathrm{m}$ (DRGs) or 14 $\mu \mathrm{m}$ (hind paw skin and sciatic nerve), and $20 \mu \mathrm{m}$ (spinal cord) thickness. Immunoreactivities were visualized by tyramide signal amplification system (TSA Plus; NEN Life Science Products, Boston, MA) as described previously. ${ }^{33}$ To perform colocalization study in DRG sections, adjacent ones $(5 \mu \mathrm{m})$ were used for staining with different primary antibodies. In spinal cord, sciatic nerve or skin of hind paws, TSA Plus staining was performed, followed by indirect immunohistochemistry, ${ }^{34}$ visualized by lissamine rhodamine sulfonylchlorideconjugated donkey anti-rabbit or mouse antibodies (1:100; Jackson Immuno Research, West Grove, PA, USA). Information for primary antibodies used in this study was provided in Table 1.

The specificity of anti-GIRK3 polyclonal antibody was confirmed by immunohistochemistry using brain samples from GIRK3-KO mice. ${ }^{35}$ To detect IB4-binding neurons, the sections were incubated with isolectin B4 (IB4) (Griffonia simplicifolia I, $2.5 \mathrm{~g} / \mathrm{mL}$; Vector Laboratories, 
Table I Primary Antibody List

\begin{tabular}{|c|c|c|c|c|c|}
\hline Antibody & Host Species & Experiment & Dilution & Supplier/Catalogue No. & Characterization \\
\hline GIRK3 & Rabbit & IHC (TSA) & $1: 5,000$ & Professor M. Watanabe & Aguado et $\mathrm{al}^{35}$ \\
\hline GIRK3 & Rabbit & IHC (Coons) & $1: 1,000$ & Professor M. Watanabe & Aguado et $\mathrm{al}^{35}$ \\
\hline GIRK3 & Rabbit & WB & $1: 400$ & Professor M. Watanabe & Aguado et $\mathrm{al}^{35}$ \\
\hline CGRP & Rabbit & IHC (Coons) & $1: 2,000$ & S.I. Grigis & Orazzo et $\mathrm{al}^{46}$ \\
\hline NF200 & Mouse & IHC (Coons) & $\mathrm{l}: 400$ & Sigma/NOI42 & Perry et $\mathrm{al}^{47}$ \\
\hline Gal & Rabbit & IHC (Coons) & $\mathrm{I}: 4,000$ & E. Theodorsson & Perry et $\mathrm{al}^{47}$ \\
\hline NPY & Rabbit & IHC (Coons) & $\mathrm{I}: 400$ & Walsh and Wong & Shi et $\mathrm{al}^{41}$ \\
\hline PGP9.5 & Rabbit & IHC (Coons) & $\mathrm{I}: 400$ & Swant/PV 25 & Brumovsky et $\mathrm{a}^{48}$ \\
\hline$\beta$-actin & Mouse & WB & $1: 5000$ & Sigma/A544I & Lyu et $\mathrm{al}^{22}$ \\
\hline
\end{tabular}

Burlingame, CA), followed by incubation with a goat antiGSA I antiserum (1:2,000; Vector Laboratories).

\section{Western Blot}

On day 14 following axotomy, the contra- and ipsilateral DRGs (L4-5) were respectively collected, and then immediately snap frozen on dry ice. The tissues were roughly broken with knife and placed in lysis buffer containing protease inhibitor (P8340; Sigma), followed by sonication. The lysates were centrifuged for $30 \mathrm{~min}$ under $10,000 \times \mathrm{g}$ at $4{ }^{\circ} \mathrm{C}$, and the supernatants were used for Western blot analysis according to our previous procedures. ${ }^{22}$ Briefly, $20 \mu \mathrm{g}$ of protein was loaded on $10 \%$ SDS-PAGE gel and transferred to polyvinylidene fluoride membrane (Millipore, Hemel, Hempstead, UK). The anti-GIRK3 polyclonal antibody used in this study is known to recognize a protein of $\sim 45 \mathrm{kD}$ protein in WT cerebellum, but absent in either GIRK3-KO or GIRK2/3-KO mice. ${ }^{35}$ The $\beta$-actin was used as a loading control.

\section{Image Analysis and Quantification}

The sections were analysed in a confocal scanning microscope (Bio-Rad, Hemel, Hempstead, UK) equipped with $\times 10$ $(0.5 \mathrm{NA}), \times 20(0.75 \mathrm{NA})$ and $\times 63$ oil $(1.40 \mathrm{NA})$ objectives. In some experiments, a LSM 700 confocal microscope (Zeiss, Oberkochen, Germany) was used as described in previous studies. ${ }^{33,36}$ The quantification was performed following the same set as in a previous report. ${ }^{22}$

\section{Statistical Analysis}

The statistical results were expressed as mean \pm SEM. Percentages of GIRK3 immunoreactive (-IR) neuron profiles (NPs) were evaluated by unpaired Student's $t$-test between contra- and ipsilateral DRGs. The band intensity in Western blot and fluorescence levels for GIRK3-like immunoreactivity (LI) in proximal and distal sciatic nerve was performed by densitometry with Image J software.

\section{Results}

\section{Expression of GIRK3 in Control DRGs}

In this study, the immunofluorescent signal of GIRK3 was observed in rat DRGs but was undetectable when the antiGIRK3 antibody was pre-incubated with the homologous antigen in an absorption test (Figure 1A vs. D). High power immunofluorescence micrographs showed that the GIRK3-LI was largely accumulated in a punctate pattern in the cytoplasm surrounding the nucleus (Figure 1C).

Based on previously described classification principle, DRG neurons were grouped into three subpopulations using neuronal markers calcitonin gene-related peptide (CGRP), IB4 and neurofilament 200 (NF200). ${ }^{37}$ CGRP, IB4 and NF200 were used to label small peptidergic, small non-peptidergic, and medium-sized and large myelinated neurons, respectively. GIRK3-LI was detected in peptidergic and non-peptidergic NPs with a broad size spectrum, including small, mediumsized and large ones (Figure 1A, B and E-M). Quantification results showed $\sim 41 \%, \sim 48 \%$ and $\sim 45 \%$ of GIRK3-IR NPs expressed CGRP, IB4 and NF200, respectively. Conversely, $\sim 38 \%, 54 \%$ and $\sim 44 \%$ CGRP-IR, IB4-IR and NF200-IR NPs expressed GIRK3, respectively (Figure 1N).

\section{GIRK3 in Hind Paws and Sciatic Nerve}

In rat glabrous skin of hind paws, GIRK3-LI was seen within the dermis layer (Figure 2A-C2). GIRK3-LI co-localized with CGRP and PGP9.5 in nerve terminals (Figure 2A-C2, D-F). GIRK3-LI was intensively expressed in the nerve bundles, as well as epineurium in the dermal layer of the hind paw skin (Figure 2G-I). In addition, GIRK3-LI was also observed in non-neuronal cells (Figure 2A2-C2). GIRK3 was expressed in 

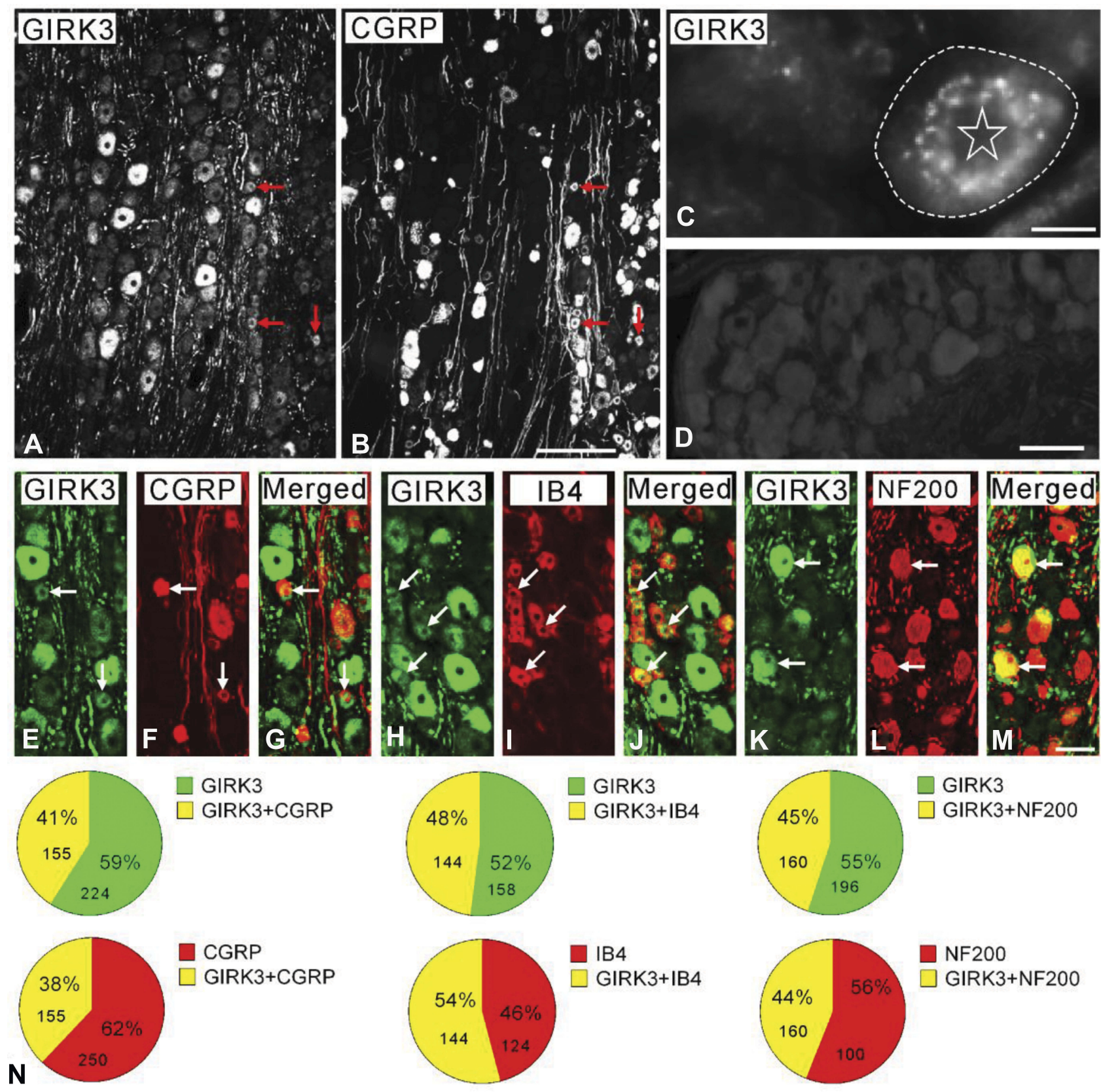

Figure I GIRK3 co-localizes with neuronal markers in control DRGs. (A, B) Arrows indicate the neurons expressing GIRK3 (A) and CGRP (B). (C) High magnification immunofluorescence micrograph shows punctate distribution of GIRK3-LI in the cytoplasm surrounding the nucleus. The dashed line indicates cellular border. The asterisk indicates nucleus. (D) GIRK $3^{+}$signal is absent after pre-incubation of the antibodies with $10^{-6} \mathbf{M}$ immunogen in the absorption test. (E-M) GIRK3-LI (E, H, K) co-localizes with CGRP (F), IB4 (I) and NF200 (L) indicated by the arrows, respectively. (G), (J) and (M) are merged images. (N) Pie-graphs show the proportion of co-localization of GIRK3 with each marker in control DRGs. The labeled number indicates counted NPs. Scale bars indicate $100 \mu \mathrm{m}(\mathbf{A}, \mathbf{B}), 50 \mu \mathrm{m}(\mathbf{E}-\mathbf{M})$ and $20 \mu \mathrm{m}(\mathbf{C}, \mathbf{D})$.

intact sciatic nerve and co-localized with CGRP, IB4 and PGP9.5, respectively (Figure 3).

\section{Upregulation of GIRK3 in Axotomized DRGs}

On day 14 following axotomy, a significant upregulation in the percentage of GIRK3-IR NPs was observed in injured DRGs (ipsi vs. contra; $38.5 \pm 0.9 \%$ vs. $17.1 \pm$ $0.8 \% ;{ }^{* * *} p<0.001, \mathrm{n}=5$ ) (Figure $4 \mathrm{~A}-\mathrm{C}$ ). The relative levels of GIRK3 were also confirmed to be upregulated in the ipsilateral as compared to contralateral DRGs (from two rats, the same side of DRGs was pooled) by Western blot (Figure 4D). Of note, only one strong band with predicted molecular weight was observed in the intact 


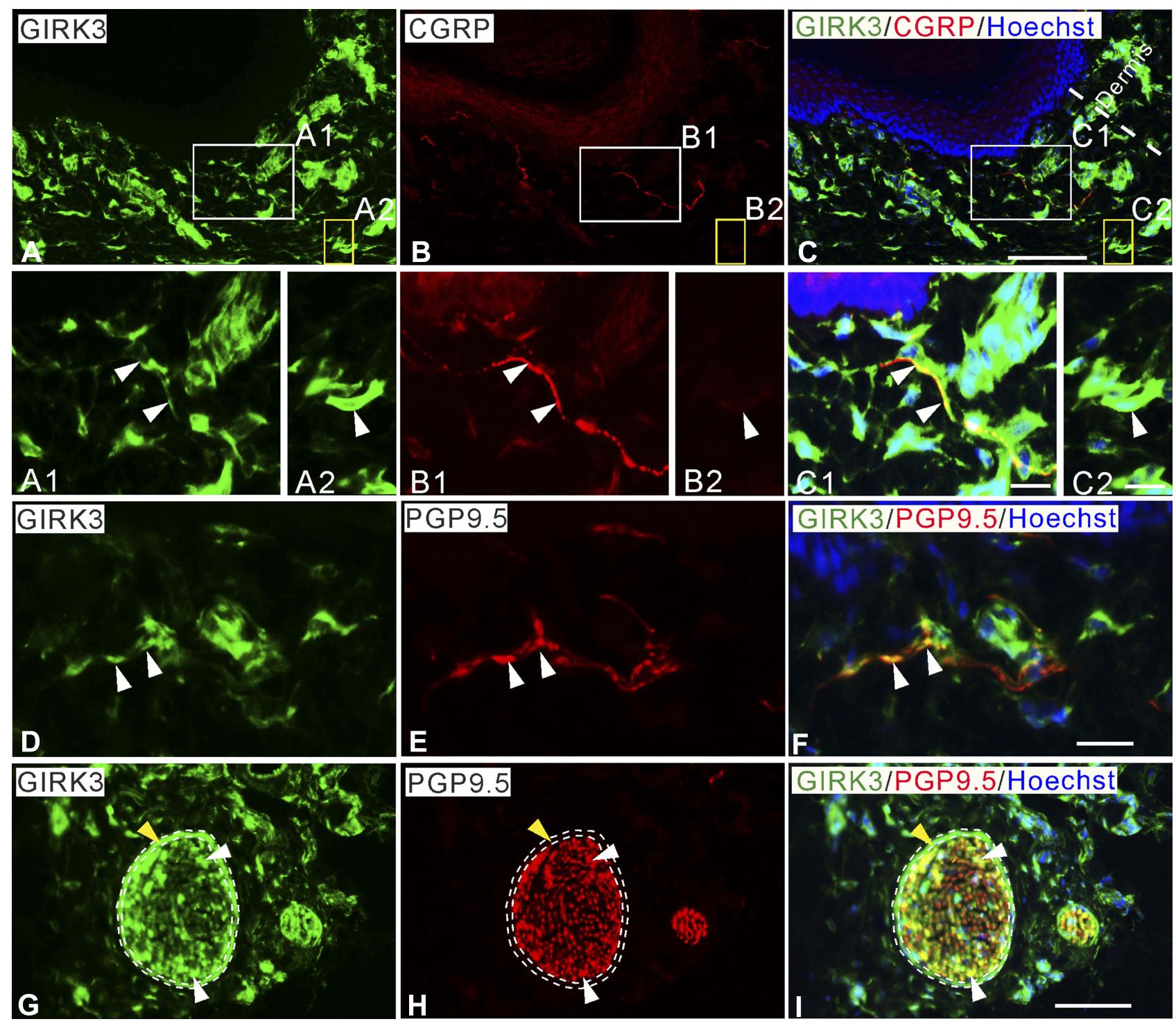

Figure 2 Characteristics of GIRK3 expression in skin of hind paw. (A-C) A large amount of GIRK3-LI (A) is seen in upper dermis, some co-localize with CGRP ${ }^{+}$fibers $(\mathbf{B})$ (AI, BI, CI) High magnification of immunofluorescence micrographs shows the co-localized fibers of GIRK3-LI (AI; arrowheads) and CGRP-LI (BI; arrowheads). (A2, B2, C2) Some GIRK3 ${ }^{+}$(A2; arrowheads), but CGRP ${ }^{-}$(B2; arrowheads) fibers are seen in the upper dermis. (D-F) GIRK3 ${ }^{+}$fibers $\left(\mathbf{D}\right.$; arrowheads) are also PGP9.5 ${ }^{+}$(E) arrowheads) in upper dermis. (G-I) GIRK3-LI (G) co-localizes with PGP9.5-LI (H) largely in nerve bundles (white arrowheads) and epineurium (yellow arrowheads) in lower dermis (I). Scale bars indicate $100 \mu \mathrm{m}(\mathbf{A}-\mathbf{C}, \mathbf{G}-\mathbf{I})$ and $20 \mu \mathrm{m}(\mathbf{A} \mathbf{I}-\mathbf{C 2}, \mathbf{D}-\mathbf{F})$.

membrane for Western blot, further confirming the antibody specificity (Figure 4D).

The 29-amino acid neuropeptide (30 in humans) galanin (Gal) and the 36-amino acid neuropeptide Y (NPY) are often used as indicators of nerve injury-associated outcomes. Under normal condition, NPY is usually undetectable in rat DRGs but its mRNA and protein levels are dramatically increased, predominantly in medium-sized and large NPs, after peripheral nerve injury. ${ }^{38-41} \mathrm{Gal}$ is expressed in a small portion $(<5 \%)$ of DRG NPs, but is strongly upregulated (up to $50 \%$ ) in injured DRGs, with peak levels on 7-14 days after axotomy, at both mRNA and protein levels. ${ }^{42,43}$ In the present study, $\sim 56 \%$ and $\sim 51 \%$ of GIRK3-positive $\left(^{+}\right)$NPs co-expressed NPY and Gal 14 days after axotomy, respectively (Figure $4 \mathrm{E}-\mathrm{K}$ ). Conversely, $\sim 85 \%$ of $\mathrm{NPY}^{+}$and $\sim 49 \%$ of $\mathrm{Gal}^{+}$NPs were GIRK3 ${ }^{+}$, respectively (Figure 4E-K).

\section{Peripheral Nerve Injury Induced an Upregulation of GIRK3 in Spinal Dorsal Horn}

GIRK3-LI was mainly observed in the superficial layers of dorsal horn (Figure 5A, D and I). The GIRK3-LI was absent in the absorption test (Figure 5B). $\mathrm{CGRP}^{+}$fibers 

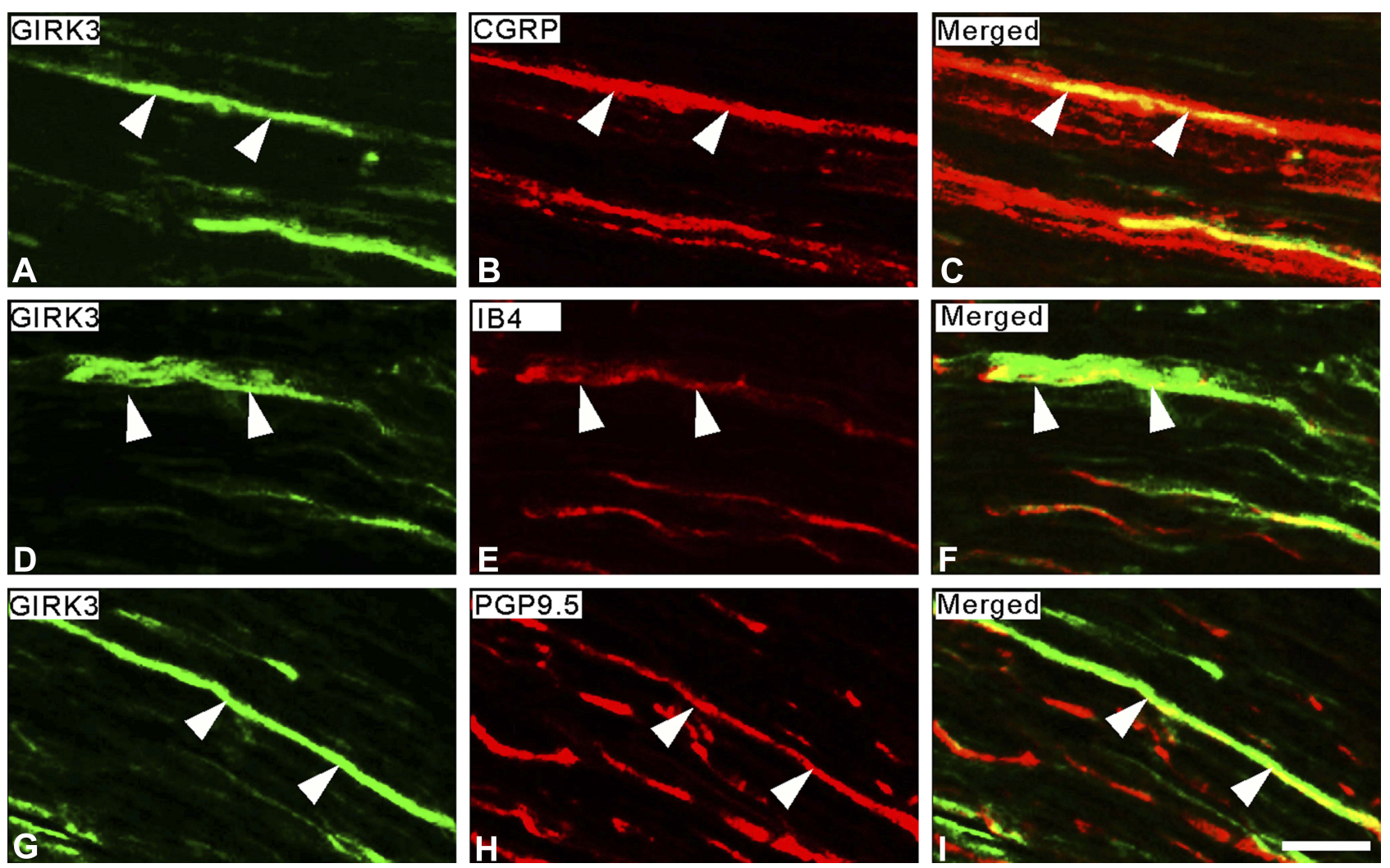

Figure 3 Expression of GIRK3-LI in sciatic nerve. (A-C) Double-staining shows a few GIRK3 ${ }^{+}$fibers $(\mathbf{A})$ are CGRP ${ }^{+}$(B) in sciatic nerve. (D-F) Some GIRK3 ${ }^{+}$fibers $(\mathbf{D})$ are IB4 ${ }^{+}(\mathbf{E})$. (G-I) GIRK3-LI (G) in sciatic nerve shows co-localization with an axonal marker PGP9.5 (H). Arrowheads indicate the co-localization of GIRK3-LI with each marker in sciatic nerve. (C), (F), and (I) are merged images. Scale bar indicates $20 \mu \mathrm{m}(\mathbf{A}-\mathrm{I})$

were found in lamina I and II with some extension to the deeper laminae (Figure 5C). GIRK3-IR interneurons were found in deeper laminae, but not superficial layers (Figure 5D, E, G and H). These interneurons were CGRPnegative (Figure $5 \mathrm{~F}-\mathrm{H}$ ). An increase of $\mathrm{GIRK}^{+}$processes was detected in the ipsilateral as compared with the contralateral dorsal horn on day 14 after axotomy (Figure 5I).

\section{Axonal Transport of GIRK3}

Spinal dorsal rhizotomy was performed unilaterally. After rhizotomy, CGRP-LI was largely reduced in the ipsilateral dorsal horn as compared with contralateral one (Figure 6A vs B). Similar to that of CGRP, GIRK $3^{+}$signals were mostly eliminated in the ipsilateral dorsal horn after rhizotomy, indicating an anterograde transport of GIRK3 from peripheral sensory neurons to central spinal cord (Figure 6C vs D). Sciatic nerve crush caused an accumulation of GIRK 3 at the injured site where GIRK3-LI was significantly stronger in proximal than distal sites (Figure 6E and F), thus indicating both anterograde and retrograde transport of GIRK3 in DRG neurons.

\section{Discussion}

We have recently investigated the expression and regulation of GIRK1 and -2 in rat DRGs and spinal cord following peripheral nerve injury. ${ }^{22}$ In the present study, similar methods have been employed to analyze the expression of GIRK3 in rat DRGs and spinal cord. GIRK3 was expressed in $\sim 17 \%$ of the DRG NPs and significantly increased after axotomy (to around $39 \%$ ). This contrasts with the expression of both GIRK1 and -2 , for which the corresponding proportions in controls were $\sim 70 \%$ and $<10 \%$, respectively, and both were downregulated (to $\sim 55 \%$ and $<2 \%$, respectively). GIRK 3 was also detected in the spinal dorsal horn and also increased after axotomy.

Using RNA-seq, Flegel and colleagues investigated the expression of $\mathrm{G}$ protein-coupled receptors and ion channels in human sensory ganglia, including DRGs and trigeminal ganglia. ${ }^{12}$ All GIRK channel subunits were found in human DRGs, with a highest expression level of GIRK1, lower expression levels of GIRK3 and GIRK4, and lowest expression level of GIRK2. Our previously published results ${ }^{22}$ and results presented in this study reveal a similar expression pattern of GIRK1-3 in rats compared to humans. 


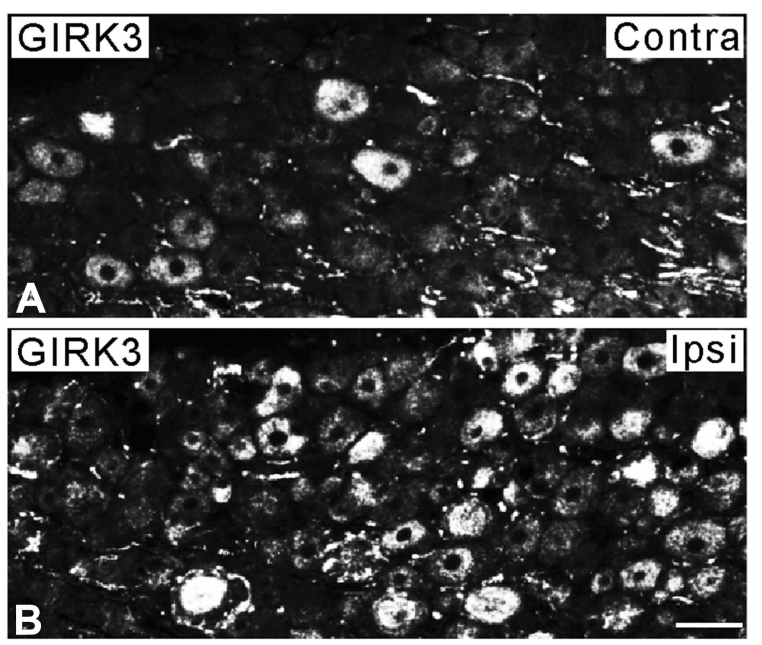

\section{GIRK3}

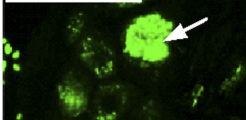

$\therefore \quad 4$

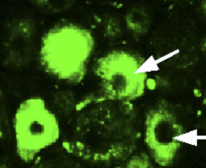

4

sy bes

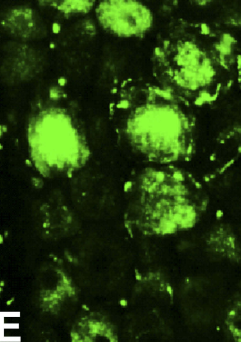

E

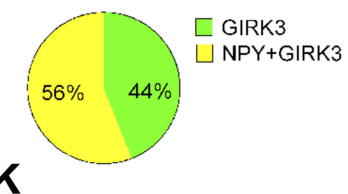

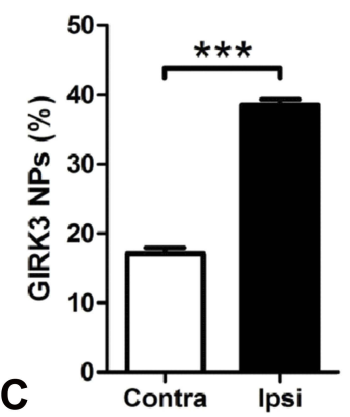
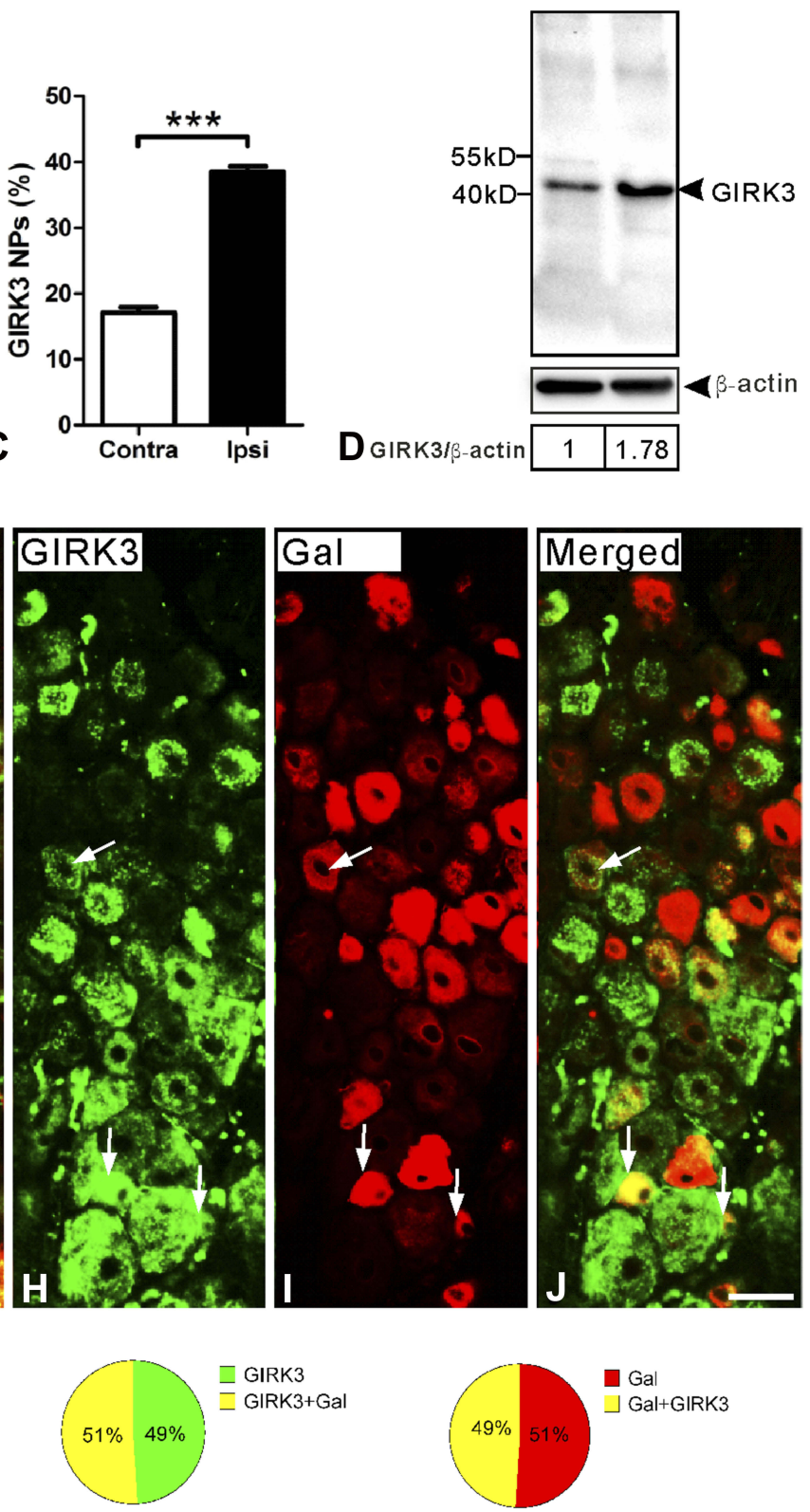

Figure 4 GIRK3 is upregulated in DRGs 14 days after axotomy. (A, B) Immunofluorescence micrographs show GIRK3-LI in contra- and ipsilateral DRGs, respectively. (C) Quantification analysis shows percentage of GIRK3 ${ }^{+} \mathrm{NPs}$ is significantly higher in ipsilateral compared to contralateral DRGs after axotomy $(\mathrm{n}=5$ per group; $* * * p<0.00 \mathrm{I})$ (D) Western blot shows total protein of GIRK3 in DRGs is upregulated after axotomy. (E-G) GIRK3 (E) co-localizes with NPY (F) shown by arrows in ipsilateral DRGs. $(\mathbf{H}-\mathbf{J})$ GIRK3 $(\mathbf{H})$ co-localizes with Gal (I) shown by arrows in ipsilateral DRGs. (G) and (J) are merged images. (K) Pie-graphs show the proportion of DRG neurons exhibiting co-localization of GIRK3 with NPY and Gal in ipsilateral DRGs, respectively. The labeled numbers indicate counted NPs. Arrows indicate co-localized neurons in (E-J). Scale bars indicate $40 \mu \mathrm{m}(\mathbf{A}, \mathbf{B})$ and $50 \mu \mathrm{m}$ (E-J).

We further detected GIRK3-LI in all three major DRG neuron subpopulations, which include neurons expressing CGRP (small peptidergic), IB4 (small non-peptidergic) or NF200 (medium-sized and large myelinated Aß), whereby each of the three was found in $40 \sim 50 \%$ of the GIRK $3^{+}$NPs. This means that there is a certain overlap, but the details still need to be sorted out. Moreover, and importantly, also GIRK1 coexpressed these three markers with the following percentages: $\sim 17 \%, \sim 51 \%$ and $\sim 39 \%{ }^{22}$ This indicates a potential for interaction of GIRK3 with GIRK1 to form heterotetramer channels in the subpopulations of DRG neurons. In contrast, none of the GIRK2 ${ }^{+}$neurons expressed CGRP, but a high percentage IB4 $(\sim 73 \%)$ and a lower percentage NF200 $(\sim 32 \%){ }^{22}$ Thus, our findings suggest a possible interaction 


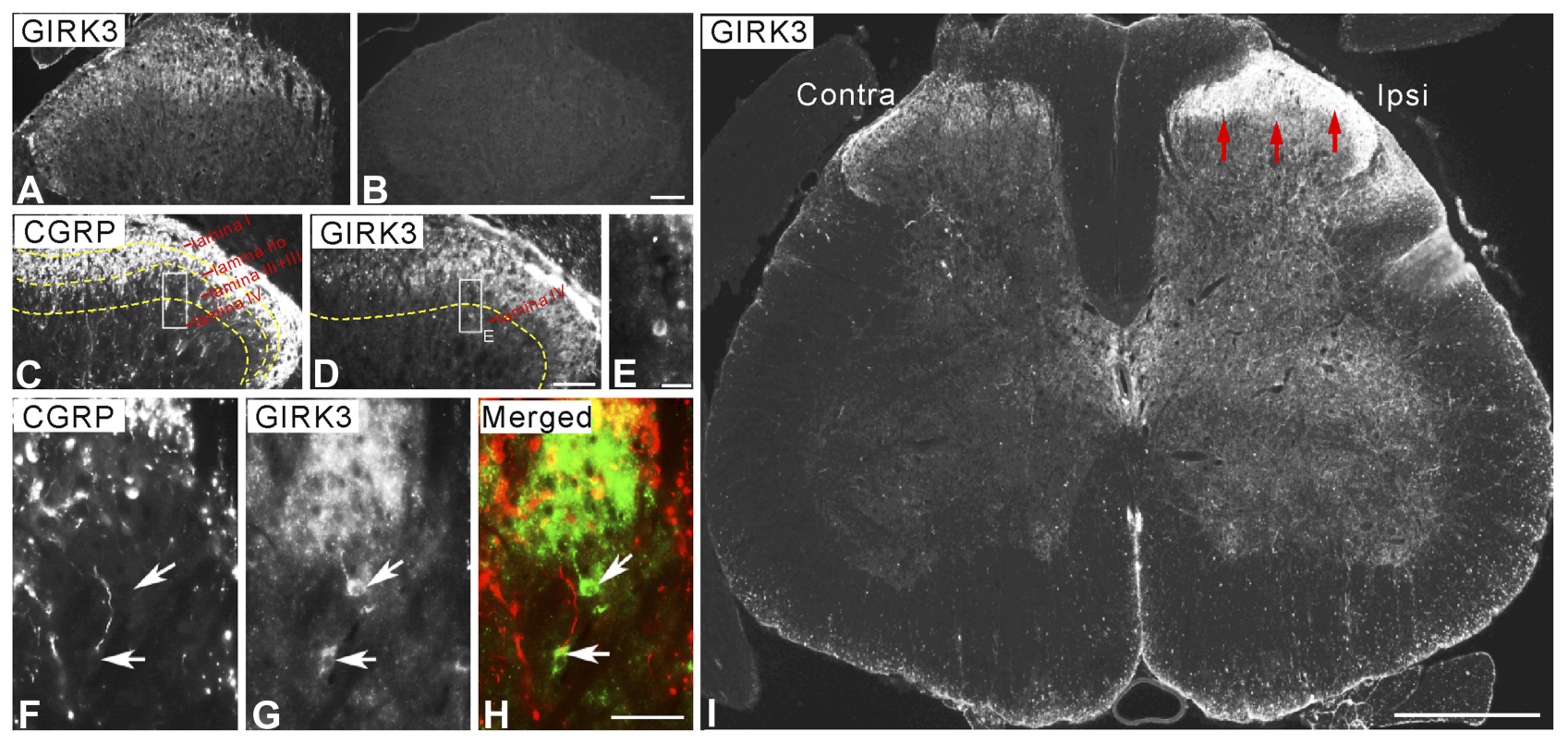

Figure 5 Expression and regulation of GIRK3 in spinal cord. GIRK3-LI is present in control dorsal horn (A), and is absent after pre-incubation of the antibody with $10^{-6}$ M immunogen in the absorption test (B). (C, D) GIRK3-LI (D) is largely localized in the superficial laminae but much weaker than CGRP-LI (C), and also present in a few interneurons in deeper laminae (E, G, H). Representative micrographs show $\mathrm{GIRK}^{+}\left(\mathbf{G}\right.$ and $\mathbf{H}$; arrows) but CGRP ${ }^{-}$(F; arrows) interneurons in deeper laminae $(\mathrm{GIRK3}$, green; CGRP, red). (I) Fourteen days after axotomy, a dramatic upregulation of GIRK3-LI (red arrows) is seen on the ipsilateral (ipsi) as compared to contralateral (contra) spinal dorsal horn. Scale bars indicate $500 \mu \mathrm{m}(\mathbf{I}), 100 \mu \mathrm{m}(\mathbf{A}-\mathbf{D}), 50 \mu \mathrm{m}(\mathbf{F}-\mathbf{H})$ and $25 \mu \mathrm{m}(\mathbf{E})$.
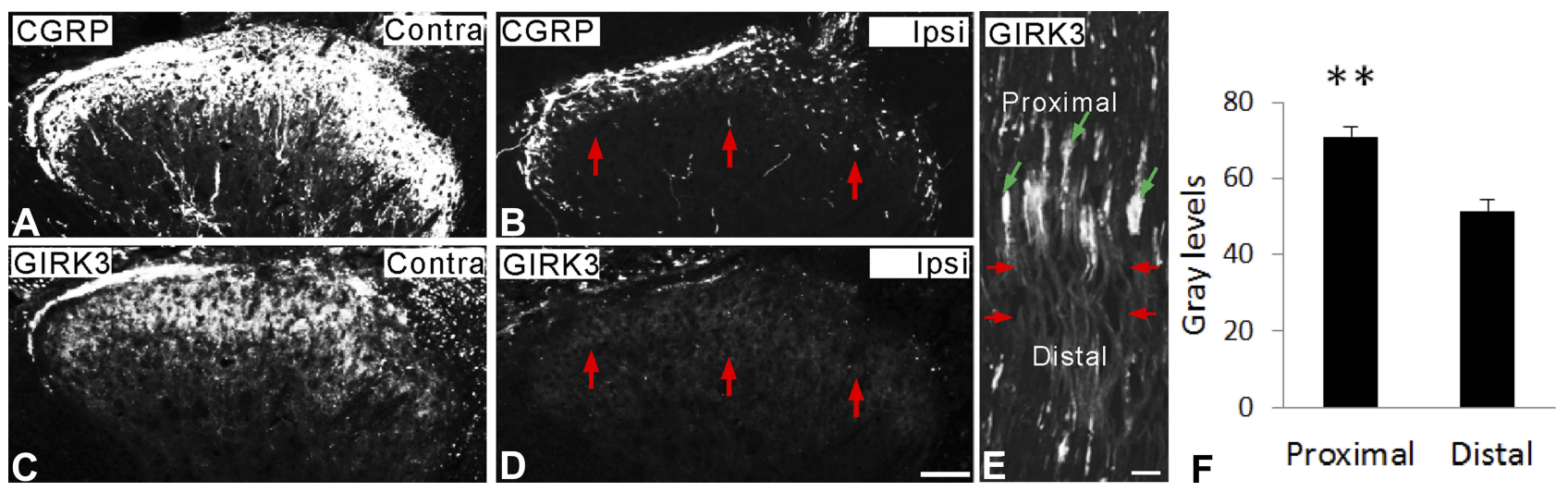

Figure 6 Axonal transport of GIRK3. (A-D) Fourteen days after unilateral dorsal rhizotomy, both CGRP- and GIRK3-Lls are largely decreased (red arrows) in ipsilateral dorsal horn compared to contralateral one. (E, F) Ten hours after sciatic nerve crush (red arrows indicate injured site), significant more GIRK3-LI is accumulated on the proximal side of the crush (green arrows) than the distal side $(n=3$; ** $p<0.01)$. Scale bars indicate $100 \mu \mathrm{m}(\mathbf{A}-\mathbf{D})$ and $50 \mu \mathrm{m}(\mathbf{E})$.

between GIRK3 and GIRK2 in non-peptidergic and myelinated neurons. We found a large amount of GIRK3-LI surrounding the nucleus in the cytoplasm without clear membrane localization. This maybe because that GIRK3 lacks an endoplasmic reticulum (ER) export signal ${ }^{29}$ and therefore it is retained in the ER after translation. In addition, GIRK1 but not GIRK2 or 4 also lacks an ER export signal. Thus, the GIRK1 is mostly not seen on the membrane. ${ }^{22}$

$\mathrm{GIRK}^{+}{ }^{+}$processes were seen in the superficial layers of spinal dorsal horn, especially in the lamina II. Interestingly,
$\mathrm{GIRK}^{+}{ }^{+}$and $\mathrm{GIRK} 2^{+}$processes were also found abundantly in the lamina II. However, only accountable GIRK3 ${ }^{+}$interneurons were seen in the deeper spinal dorsal horn laminae. Thus, most of GIRK $3{ }^{+}$fibers in the dorsal horn presumably originate in DRGs. This is supported by our findings (i) sciatic nerve crush causes an accumulation of GIRK3 on proximal side indicating the existence of anterograde fast axonal transport; and, especially, (ii) GIRK3-LI was completely eliminated in the ipsilateral dorsal horn after dorsal root rhizotomy. Thus, the majority of GIRK3 is located in the presynaptic terminals of 
sensory input to the spinal cord, indicating a role in modulating spinal nociceptive processing at the presynaptic level. In contrast, much more GIRK1 and -2 LIs were detected in local dorsal horn neurons. Moreover, both GIRK1 and -2 are axonally transported, ${ }^{22}$ and they are also present in afferent nerve endings. These two subunits may thus have both presynaptic actions as well as controlling signalling in postsynaptic dorsal horn interneurons.

It has been demonstrated that several types of potassium $\left(\mathrm{K}^{+}\right)$channel-components are downregulated by peripheral nerve injury in somatosensory system, including voltagegated $\mathrm{K}^{+}$channels, two-pore-domain $\mathrm{K}^{+}$channels, calcium ${ }^{2}$ ${ }^{+}$-activated $\mathrm{K}^{+}$channels, ATP-sensitive $\mathrm{K}^{+}$channels and inwardly-rectifying $\mathrm{K}^{+}$channels. $^{2,44,45}$ The activation of these $\mathrm{K}^{+}$channels can induce $\mathrm{K}^{+}$outflow and cause the membrane potential of neurons more negative, which is more inhibited. Here, we reported an upregulation of GIRK3 in both DRGs and dorsal horn following peripheral nerve injury, which is in contrast to the downregulation of most of the other $\mathrm{K}^{+}$channel-components as listed above. These data reflect a unique and complex role of GIRK3 in the sensory neurons. Considering a role of GIRK3 in reducing the number of other GIRK channels on the cell surface by targeting other subunits to lysosome for degradation, ${ }^{29}$ the upregulation of GIRK3 may be a possible reason for the downregulation of GIRK1 and -2 .

Gal and NPY are both strongly upregulated and have been shown to be involved in nociceptive processing, especially after peripheral nerve injury. Here, we observed that a high proportion of GIRK $3^{+}$neurons contained Gal and NPY-LIs, further supporting a role of GIRK3 in pain modulation.

\section{Concluding Remarks}

This work was an extension of our previous study on GIRK1 and -2 . Our aim was to investigate the expression and regulation of GIRK3 in sensory neurons after nerve injury. Together with our previously published data, a summary of expression of GIRK channel subunits 1-3, in rat DRGs and spinal dorsal horn, is as follows:

1. Of the three channel subunits, GIRK1 has the highest level of protein.

2. In contrast to the downregulation of GIRK 1 and -2 , GIRK3-LI is upregulated after peripheral nerve injury.

\section{Acknowledgments}

We thank Dr. Tomas Hökfelt (Karolinska Institutet) for providing the anti-GIRK3 antibody which was an original gift from Dr. Masahiko Watanabe (Hokkaido University). We thank Dr. Kaj Fried (Karolinska Institutet) for help with animal experiments. We thank Dr. Tomas Hökfelt for critical reading of the manuscript. This work was supported by the China Scholarship Council (CSC) award to Dr. Chuang Lyu (HIT, 2013), and The Research Council of Norway (811397) to A.M. and T.J.S.S.

\section{Author Contributions}

C.L., G.W.L. and T.J.S.S. performed experiments. C.L. and T.J.S.S. designed the experiments. C.L., G.W.L. and T.J.S. S. analyzed the data. J.M. and A.M. contributed reagents, materials, analysis tools and resources. C.L. and T.J.S. S. wrote the manuscript. J.M. and A.M. reviewed and revised the draft manuscript. All authors made substantial contributions to conception and design, acquisition of data, or analysis and interpretation of data; took part in drafting the article or revising it critically for important intellectual content; gave final approval of the version to be published; and agree to be accountable for all aspects of the work.

\section{Disclosure}

The authors report no conflicts of interest in this work.

\section{References}

1. Lujan R, Marron Fernandez de Velasco E, Aguado C, Wickman K. New insights into the therapeutic potential of Girk channels. Trends Neurosci. 2014;37(1):20-29. doi:10.1016/j.tins.2013.10.006

2. Hibino $\mathrm{H}$, Inanobe $\mathrm{A}$, Furutani $\mathrm{K}$, et al. Inwardly rectifying potassium channels: their structure, function, and physiological roles. Physiol Rev. 2010;90(1):291-366. doi:10.1152/physrev.00021.2009

3. Huang CL, Slesinger PA, Casey PJ, Jan YN, Jan LY. Evidence that direct binding of $\mathrm{G}$ beta gamma to the GIRK1 $\mathrm{G}$ protein-gated inwardly rectifying $\mathrm{K}+$ channel is important for channel activation. Neuron. 1995;15(5):1133-1143. doi:10.1016/0896-6273(95)90101-9

4. Huang CL, Jan YN, Jan LY. Binding of the G protein betagamma subunit to multiple regions of $\mathrm{G}$ protein-gated inward-rectifying $\mathrm{K}+$ channels. FEBS Lett. 1997;405(3):291-298. doi:10.1016/S00145793(97)00197-X

5. Ikeda K, Kobayashi T, Kumanishi T, Niki H, Yano R. Involvement of G-protein-activated inwardly rectifying $\mathrm{K}$ (GIRK) channels in opioid-induced analgesia. Neurosci Res. 2000;38:113-116. doi:10.1016/S0168-0102(00)00144-9

6. Minami M, Satoh M. Molecular biology of the opioid receptors: structures, functions and distributions. Neurosci Res. 1995;23 (2):121-145. doi:10.1016/0168-0102(95)00933-K

7. Patil N, Cox DR, Bhat D, et al. A potassium channel mutation in weaver mice implicates membrane excitability in granule cell differentiation. Nat Genet. 1995;11(2):126-129. doi:10.1038/ng10 95-126

8. Ikeda K, Kobayashi T, Kumanishi T, Niki H, Yano R. Involvement of G-protein-activated inwardly rectifying $\mathrm{K}$ (GIRK) channels in opioid-induced analgesia. Neurosci Res. 2000;38(1):113-116. doi:10.1016/S0168-0102(00)00144-9 
9. Luscher C, Jan LY, Stoffel M, Malenka RC, Nicoll RA. G protein-coupled inwardly rectifying $\mathrm{K}+$ channels (GIRKs) mediate postsynaptic but not presynaptic transmitter actions in hippocampal neurons. Neuron. 1997;19(3):687-695. doi:10.1016/S0896-6273(00) 80381-5

10. Lomazzi M, Slesinger PA, Luscher C. Addictive drugs modulate GIRK-channel signaling by regulating RGS proteins. Trends Pharmacol Sci. 2008;29(11):544-549. doi:10.1016/j.tips.2008.07.011

11. Nockemann D, Rouault M, Labuz D, et al. The K + channel GIRK2 is both necessary and sufficient for peripheral opioid-mediated analgesia. EMBO Mol Med. 2013;5(8):1263-1277. doi:10.1002/ emmm.v5.8

12. Flegel C, Schöbel N, Altmüller J, et al. RNA-Seq analysis of human trigeminal and dorsal root ganglia with a focus on chemoreceptors. PLoS One. 2015;10(6):e0128951. doi:10.1371/journal.pone.0128951

13. Gao XF, Zhang HL, You ZD, Lu CL, He C. G protein-coupled inwardly rectifying potassium channels in dorsal root ganglion neurons. Acta Pharmacol Sin. 2007;28(2):185-190. doi:10.1111/ j.1745-7254.2007.00478.x

14. Zhang H, Dougherty PM. Enhanced excitability of primary sensory neurons and altered gene expression of neuronal ion channels in dorsal root ganglion in paclitaxel-induced peripheral neuropathy. Anesthesiology. 2014;120(6):1463-1475. doi:10.1097/ ALN.0000000000000176

15. Usoskin D, Furlan A, Islam S, et al. Unbiased classification of sensory neuron types by large-scale single-cell RNA sequencing. Nat Neurosci. 2015;18(1):145-153. doi:10.1038/nn.3881

16. Uttam S, Wong C, Amorim IS, et al. Translational profiling of dorsal root ganglia and spinal cord in a mouse model of neuropathic pain. Neurobiol Pain. 2018;4:35-44. doi:10.1016/j.ynpai.2018.04.001

17. Luger NM, Sabino MAC, Schwei MJ, et al. Efficacy of systemic morphine suggests a fundamental difference in the mechanisms that generate bone cancer vs inflammatory pain. Pain. 2002;99 (3):397-406. doi:10.1016/S0304-3959(02)00102-1

18. Gonzalez-Rodriguez S, Hidalgo A, Baamonde A, Menendez L. Involvement of $\mathrm{Gi} / \mathrm{o}$ proteins and GIRK channels in the potentiation of morphine-induced spinal analgesia in acutely inflamed mice. Naunyn-Schmiedeberg's Arch Pharmacol. 2010;381(1):59-71. doi:10.1007/s00210-009-0471-3

19. Morrone LA, Scuteri D, Rombola L, Mizoguchi H, Bagetta G. Opioids resistance in chronic pain management. Curr Neuropharmacol. 2017;15(3):444-456. doi:10.2174/1570159X14666161101092822

20. Bedini A, Spampinato SM. Innovative opioid peptides and biased agonism: novel avenues for more effective and safer analgesics to treat chronic pain. Curr Med Chem. 2017;25(32):3895-916.

21. Basurto Ona X, Rigau Comas D, Urrutia G. Opioids for acute pancreatitis pain. Cochrane Database Syst Rev. 2013;7:CD009179.

22. Lyu C, Mulder J, Barde S, et al. G protein-gated inwardly rectifying potassium channel subunits 1 and 2 are down-regulated in rat dorsal root ganglion neurons and spinal cord after peripheral axotomy. Mol Pain. 2015;11(1):44. doi:10.1186/s12990-015-0044-z

23. Luscher C, Slesinger PA. Emerging roles for G protein-gated inwardly rectifying potassium (GIRK) channels in health and disease. Nat Rev Neurosci. 2010;11(5):301-315. doi:10.1038/nrn2834

24. Jelacic TM, Sims SM, Clapham DE. Functional expression and characterization of G-protein-gated inwardly rectifying $\mathrm{K}+$ channels containing GIRK3. J Membr Biol. 1999;169(2):123-129. doi:10.1007/s002329900524

25. Koyrakh L, Luján R, Colón J, et al. Molecular and cellular diversity of neuronal G-protein-gated potassium channels. J Neurosci. 2005;25 (49):11468-11478. doi:10.1523/JNEUROSCI.3484-05.2005

26. Kozell LB, Walter NA, Milner LC, Wickman K, Buck KJ. Mapping a barbiturate withdrawal locus to a $0.44 \mathrm{Mb}$ interval and analysis of a novel null mutant identify a role for Kcnj9 (GIRK3) in withdrawal from pentobarbital, zolpidem, and ethanol. J Neurosci. 2009;29 (37):11662-11673. doi:10.1523/JNEUROSCI.1413-09.2009
27. Pravetoni M, Wickman K. Behavioral characterization of mice lacking GIRK/Kir3 channel subunits. Genes Brain Behav. 2008;7 (5):523-531. doi: $10.1111 / \mathrm{gbb} .2008 .7$.issue-5

28. Arora D, Haluk DM, Kourrich S, et al. Altered neurotransmission in the mesolimbic reward system of Girk mice. J Neurochem. 2010;114 (5):1487-1497. doi:10.1111/j.1471-4159.2010.06864.x

29. Ma D, Zerangue N, Raab-Graham K, et al. Diverse trafficking patterns due to multiple traffic motifs in G protein-activated inwardly rectifying potassium channels from brain and heart. Neuron. 2002;33 (5):715-729. doi:10.1016/S0896-6273(02)00614-1

30. Shi TJ, Tandrup T, Bergman E, et al. Effect of peripheral nerve injury on dorsal root ganglion neurons in the $\mathrm{C} 57 \mathrm{BL} / 6 \mathrm{~J}$ mouse: marked changes both in cell numbers and neuropeptide expression. Neuroscience. 2001;105(1):249-263. doi:10.1016/S0306-4522(01) 00148-8

31. Shi TJ, Liu S-XL, Hammarberg H, et al. Phospholipase C $\{$ beta $\} 3$ in mouse and human dorsal root ganglia and spinal cord is a possible target for treatment of neuropathic pain. Proc Natl Acad Sci U S A. 2008;105(50):20004-20008. doi:10.1073/pnas.0810899105

32. Dahlstrom AB, Li JY. Fast and slow axonal transport-different methodological approaches give complementary information: contributions of the stop-flow/crush approach. Neurochem Res. 1994;19 (11):1413-1419. doi:10.1007/BF00972470

33. Shi T-JS, Xiang Q, Zhang M-D, et al. Secretagogin is expressed in sensory CGRP neurons and in spinal cord of mouse and complements other calcium-binding proteins, with a note on rat and human. Mol Pain. 2012;8:80. doi:10.1186/1744-8069-8-80

34. Mulder J, Björling E, Jonasson K, et al. Tissue profiling of the mammalian central nervous system using human antibody-based proteomics. mol Cell Proteom. 2009;8(7):1612-1622. doi:10.1074/ mcp.M800539-MCP200

35. Aguado C, Colón J, Ciruela F, et al. Cell type-specific subunit composition of $\mathrm{G}$ protein-gated potassium channels in the cerebellum. $J$ Neurochem. 2008;105(2):497-511. doi:10.1111/ j.1471-4159.2007.05153.x

36. Shi T-JS, Xiang Q, Zhang M-D, et al. Somatostatin and its $2 \mathrm{~A}$ receptor in dorsal root ganglia and dorsal horn of mouse and human: expression, trafficking and possible role in pain. Mol Pain. 2014;10:12. doi:10.1186/1744-8069-10-12

37. McMahon SB, Priestley JV. Nociceptor plasticity. In: Hunt SP, Koltzenburg M, editors. The Neurobiology of Pain. Oxford Univ Press; 2005:35-64.

38. Gibson SJ, Polak JM, Allen JM, et al. The distribution and origin of a novel brain peptide, neuropeptide $\mathrm{Y}$, in the spinal cord of several mammals. J Comp Neurol. 1984;227(1):78-91. doi:10.1002/(ISSN) 1096-9861

39. Wakisaka S, Kajander KC, Bennett GJ. Increased neuropeptide Y (NPY)-like immunoreactivity in rat sensory neurons following peripheral axotomy. Neurosci Lett. 1991;124(2):200-203. doi:10.1016/ 0304-3940(91)90093-9

40. Corness J, Shi TJ, Xu ZQ, Brulet P, Hokfelt T. Influence of leukemia inhibitory factor on galanin/GMAP and neuropeptide $\mathrm{Y}$ expression in mouse primary sensory neurons after axotomy. Exp Brain Res. 1996;112(1):79-88. doi:10.1007/BF00227180

41. Shi TJ, Cui JG, Meyerson BA, Linderoth B, Hokfelt T. Regulation of galanin and neuropeptide $\mathrm{Y}$ in dorsal root ganglia and dorsal horn in rat mononeuropathic models: possible relation to tactile hypersensitivity. Neuroscience. 1999;93(2):741-757. doi:10.1016/ S0306-4522(99)00105-0

42. Hokfelt T, Wiesenfeld-Hallin Z, Villar M, Melander T. Increase of galanin-like immunoreactivity in rat dorsal root ganglion cells after peripheral axotomy. Neurosci Lett. 1987;83(3):217-220. doi:10.1016/ 0304-3940(87)90088-7

43. Lang R, Gundlach AL, Holmes FE, et al. Physiology, signaling, and pharmacology of galanin peptides and receptors: three decades of emerging diversity. Pharmacol Rev. 2015;67(1):118-175. 
44. Chen SR, Chen H, Yuan WX, Pan HL. Increased presynaptic and postsynaptic alpha2-adrenoceptor activity in the spinal dorsal horn in painful diabetic neuropathy. J Pharmacol Exp Ther. 2011;337 (1):285-292. doi:10.1124/jpet.110.176586

45. Du X, Gamper N. Potassium channels in peripheral pain pathways: expression, function and therapeutic potential. Curr Neuropharmacol. 2013;11(6):621-640. doi:10.2174/1570159X113119990042

46. Orazzo C, Pieribone VA, Ceccatelli S, Terenius L, Hokfelt T. CGRP-like immunoreactivity in A11 dopamine neurons projecting to the spinal cord and a note on CGRP-CCK cross-reactivity. Brain Res. 1993;600 (1):39-48. doi:10.1016/0006-8993(93)90399-8
47. Perry MJ, Lawson SN, Robertson J. Neurofilament immunoreactivity in populations of rat primary afferent neurons: a quantitative study of phosphorylated and non-phosphorylated subunits. J Neurocytol. 1991;20(9):746-758. doi:10.1007/BF01187848

48. Brumovsky P, Stanic D, Shuster S, et al. Neuropeptide Y2 receptor protein is present in peptidergic and nonpeptidergic primary sensory neurons of the mouse. J Comp Neurol. 2005;489(3):328-348. doi:10.1002/(ISSN)1096-9861

\section{Publish your work in this journal}

The Journal of Pain Research is an international, peer reviewed, open access, online journal that welcomes laboratory and clinical findings in the fields of pain research and the prevention and management of pain. Original research, reviews, symposium reports, hypothesis formation and commentaries are all considered for publication. The manuscript

Submit your manuscript here: https://www.dovepress.com/journal-of-pain-research-journa management system is completely online and includes a very quick and fair peer-review system, which is all easy to use. Visit http:// www.dovepress.com/testimonials.php to read real quotes from published authors. 